\title{
Ação afirmativa no ensino superior brasileiro: a tensão entre raça/etnia e gênero*
}

\author{
Fúlvia Rosemberg* \\ Leandro Feitosa Andrade***
}

\begin{abstract}
Resumo
O ensaio tem por objetivo refletir sobre a utilidade do conceito de não sincronia, na educação, entre desigualdades de gênero e raça. Para tanto, apresenta e discute o perfil de estudantes $e$ candidatos/as ao Programa Internacional de Bolsas de PósGraduação da Fundação Ford no Brasil, propondo interpretações referentes à sobrerepresentação feminina no ensino superior e na pós-graduação. Termina alertando sobre a necessidade de se abrir o debate sobre o melhor desempenho educacional das mulheres no contexto atual de discussão sobre ação afirmativa no ensino superior para negros e indígenas.
\end{abstract}

Palavras-chave: Ação Afirmativa, Ensino Superior, Educação e Gênero, Educação e Raça.

* Recebido para publicação em janeiro de 2008, aceito em março de 2008.

** Professora titular da PUC-SP (coordenadora do Núcleo de Estudos de Gênero, Raça e Idade) e pesquisadora da Fundação Carlos Chagas, onde coordena a sessão brasileira do Programa Internacional de Bolsas de Pós-Graduação da Fundação Ford. frosemberg@fcc.org.br

*** Professor nas Faculdades Metropolitanas Unidas e subgerente do Programa Internacional de Bolsas de Pós-Graduação da Fundação Ford, desenvolvido na Fundação Carlos Chagas. leandrofandrade@uol.com.br

cadernos pagu (31), julho-dezembro de 2008:419-437. 
Ação afirmativa no ensino superior brasileiro

Affirmative Action in Higher Education in Brazil:

Tensions between Race and Gender

\begin{abstract}
The essay is a reflection on the usefulness of the concept of non synchrony between gender and racial inequalities in education. It presents and discusses the profile of the students and candidates in the International Fellowships Program of the Ford Foundation in Brazil, proposing interpretations with respect to the overrepresentation of women in higher education and in graduate studies. It ends by calling attention to the need to open up the discussion about the better educational performance of women in the present context of the debate on affirmative action in higher education for blacks and the indigenous population.
\end{abstract}

Key Words: Affirmative Action, Higher Education, Education and Gender, Education and Race. 
Fúlvia Rosemberg e Leandro Feitosa Andrade

\begin{abstract}
...meu argumento será o de que não existem soluções simples para as questões, debatidas calorosamente, da igualdade e da diferença, dos direitos individuais e das identidades de grupo; de que posicioná-los como conceitos opostos significa perder o ponto de suas interconexões. Pelo contrário, reconhecer e manter uma tensão necessária entre igualdade e diferença, entre direitos individuais $e$ identidades grupais, é o que possibilita encontrarmos resultados melhores e mais democráticos (Scott, 2005:2).
\end{abstract}

A questão que trouxe para debater neste ensaio resulta da convergência entre estudos que um de nós vem realizando há algumas décadas sobre desigualdades de gênero e raça no sistema educacional brasileiro (Rosemberg, 1993 e 2001) e a coordenação, no Brasil, do Programa Internacional de Bolsas de Pós-Graduação da Fundação Ford (Programa IFP), que se identifica como um programa de ação afirmativa na pós-graduação.

O ponto de partida é a constatação que, desde a primeira seleção do Programa IFP no Brasil em 2002, temos recebido, de modo sistemático, uma expressiva maioria de mulheres candidatas: entre os/as 949 candidatos/as da última seleção (2007), 293 são homens (31\%) e 656 mulheres (69\%). Para discutir esta sobrerepresentação feminina, ancoramo-nos no excelente artigo de Joan W. Scott, O enigma da igualdade:

venho até vocês hoje arriscando uma 'condenação penosa', como 'uma mulher que somente tem paradoxos' a oferecer e não problemas fáceis de serem resolvidos (Scott, 2005:2). ${ }^{1}$

Trataremos da tensão entre raça-etnia e gênero no contexto dos debates atuais brasileiros sobre ação afirmativa e dessa prática de ação afirmativa na pós-graduação. Para tanto, apresentaremos brevemente o Programa IFP, depois alguns dados sobre o perfil

${ }^{1}$ Scott cita, nesta passagem, Olympe de Gouges, autora da Declaração dos Direitos da Mulher e da Cidadã (1791), feminista e revolucionária francesa. 
Ação afirmativa no ensino superior brasileiro

dos/as candidatos/as e dos/as estudantes e egressos do ensino superior brasileiro e terminaremos levantando algumas questões. ${ }^{2}$

\section{O Programa Internacional de Bolsas de Pós-Graduação da Fundação Ford (IFP)}

O Programa IFP visa contribuir para a consolidação de uma nova geração de líderes provenientes dos segmentos sociais que têm enfrentado mais intensas restrições para o acesso à educação superior, a fim de fortalecer sua participação na resolução dos desafios do século XXI. Seu pressuposto é que a educação, em nível pós-graduado, constitui uma das ferramentas para incentivar a consolidação de lideranças comprometidas com novas opções de desenvolvimento em prol da justiça e igualdade social. Para tanto, o Programa IFP oferece bolsas de mestrado e doutorado para pessoas desses segmentos sociais subrepresentados na pósgraduação e que, após o término dos estudos, se comprometam a atuar em prol de uma sociedade mais justa e igualitária (Quadro 1). Trata-se de um programa internacional criado e financiado pela Fundação Ford (escritório central sediado em Nova York, EUA), implantado, progressivamente a partir de 2000, em 22 países em desenvolvimento dos quatro continentes. ${ }^{3}$

Cada país define quais os segmentos sociais a serem privilegiados nas seleções em decorrência das particularidades locais. No Brasil, o Edital destaca que o Programa IFP, além de estar atento à igualdade de gênero, destina-se, prioritariamente, a pessoas negras ou indígenas, nascidas nas regiões Norte, Nordeste

2 Os dados sobre os/as candidatos/as brasileiros/as ao Programa IFP foram processados a partir de informações constando de seus dossiês para candidatura. Atentar que solicitamos aos/às candidatos/as, no Formulário para Candidatura, autorização para usar as informações fornecidas sob anonimato para fins de pesquisa.

${ }^{3}$ Países: África do Sul, Brasil, Chile, Egito, Filipinas, Gana, Guatemala, Índia, Indonésia, Quênia, México, Moçambique, Nigéria, Palestina, Rússia, Senegal, Tailândia, Tanzânia, Uganda e Vietnã. 
ou Centro-oeste, ou provenientes de famílias que tiveram poucas oportunidades econômicas e educacionais (Edital, 2006). Esses segmentos sociais são os que dispõem, historicamente no Brasil, de menor acesso à pós-graduação (Tabela 1).

\section{Quadro 1}

O Programa Internacional de Bolsas de Pós-Graduação da Fundação Ford (International Fellowships Program - IFP) oferece bolsas de mestrado e doutorado, no Brasil e no exterior, por até 3 anos, para que mulheres e homens, com potencial de liderança em seus campos de atuação, prossigam seus estudos capacitando-se para promover o desenvolvimento de seu país, bem como maior justiça econômica $e$ social.

A Fundação Carlos Chagas (www.fcc.org.br) é a instituição que coordena, no Brasil, o Programa Internacional de Bolsas de PósGraduação da Fundação Ford, sendo responsável pelas seleções anuais e pelo acompanhamento dos/as bolsistas.

O Programa foi implantado no Brasil em 2002, já tendo concedido 210 bolsas. Estão previstas seleções anuais até 2011 e a concessão de 40 bolsas por ano. O Programa se integra às experiências recentes de ação afirmativa $e$ vem privilegiando pessoas nascidas nas regióes Norte, Nordeste ou Centro-Oeste, de origem étnico-racial negra ou indígena e que tiveram poucas oportunidades econômicas ou educacionais (www.programabolsa.org.br).

As candidaturas são avaliadas por uma Comissão de Seleção brasileira, composta por especialistas dos diversos campos do conhecimento $e$ intervenção, apoiada por assessores ad hoc também brasileiros. 
Ação afirmativa no ensino superior brasileiro

Tabela 1

Percentual de pessoas que freqüentaram ou estão freqüentando pós-graduação, por atributo e ano. Brasil

\begin{tabular}{|l|c|c|c|c|}
\hline \multirow{2}{*}{ Variáveis } & \multicolumn{4}{|c|}{ Ano } \\
\cline { 2 - 5 } & 2002 & 2003 & 2004 & 2005 \\
\hline Sexo & 49 & 48 & 49 & 50 \\
Homens & 51 & 52 & 51 & 50 \\
Mulheres & & & & \\
\hline Cor/raça & 86 & 84 & 82 & 85 \\
Brancas e amarelas & 14 & 16 & 18 & 15 \\
Não brancas \\
(pretas, pardas, indígenas)
\end{tabular}

Fonte: PNADs (2002, 2003, 2004 e 2005).

Estar atento à igualdade de gênero tem significado, para a coordenação do Programa IFP no Brasil, atribuir um número equivalente de bolsas para homens e para mulheres. Porém, se nos atemos à racionalidade de estratégias de ação afirmativa (isto é, corrigir os vieses ou as desigualdades observadas nos indicadores da política setorial), tal solução pode ser problematizada, como discutiremos adiante.

\section{A sobrerepresentação das mulheres}

Como se sabe, o tema ação afirmativa no ensino superior é uma novidade no cenário brasileiro dos últimos 10 anos, não se dispondo de repertório de práticas consolidadas pelas gerações anteriores (Feres Júnior e Zoninsein, 2006). A reivindicação por políticas de ação afirmativa no ensino superior tem se referido, no Brasil, a dois principais segmentos sociais: egressos da escola 
pública (como indicador de oportunidades econômicas e educacionais), negros e indígenas. Da perspectiva das relações de gênero, o debate brasileiro sobre ações afirmativas direciona-se, exclusivamente, aos campos do trabalho e da política (Ligocki e Libardoni, 1995; Estudos Feministas, 1996). Assim, nos debates e textos, por exemplo, nas propostas de cotas para ingresso na universidade, praticamente não há menção à perspectiva do gênero.

No contexto do Programa IFP, no Brasil, a questão tem nos preocupado desde sua implantação, em decorrência da peculiar composição sexual de estudantes e egressos do ensino superior $e$ do expressivo número de mulheres candidatas em todas as seleções. Com efeito, as séries históricas sobre a composição sexual do conjunto de candidatos/as, desde a primeira seleção (Tabela 2), mostram um percentual de mulheres bastante superior ao de homens. Por que isso vem ocorrendo?

\section{Tabela 2}

Porcentagem de mulheres candidatas, por ano da seleção.

Seleção IFP Brasil.

\begin{tabular}{|l|c|c|c|c|c|}
\hline 2002 & 2003 & 2004 & 2005 & 2006 & 2007 \\
\hline 66,6 & 67,6 & 66,9 & 68,0 & 72,0 & 69,1 \\
\hline
\end{tabular}

Fonte: Base de dados do Programa Internacional de Bolsas de Pósgraduação da Fundação Ford, Brasil (FCC, 2007).

Uma primeira resposta seria, simplesmente, que recebemos maior número de candidaturas de mulheres porque um maior número de mulheres que de homens ingressam e terminam o curso superior no Brasil. De fato, diferentemente do senso comum, as mulheres brasileiras, de todos os segmentos de cor/raça (com exceção da "amarela")", apresentam melhores

${ }^{4}$ A terminologia usada pelo Instituto Brasileiro de Geografia e Estatística (IBGE) no quesito cor/raça propõe cinco alternativas: branca, preta, parda, amarela (isto é, de ascendência asiática) e indígena (ver Rocha e Rosemberg, 2007). 
Ação afirmativa no ensino superior brasileiro

indicadores educacionais do que os homens, especialmente a partir do ensino médio.

Assim, várias pesquisas já mostraram que mulheres negras (pretas e pardas), apesar de apresentarem piores indicadores que mulheres brancas, apresentam melhores indicadores educacionais que homens negros, da mesma forma que mulheres brancas apresentam melhores indicadores educacionais que homens brancos (Barcelos, 1993; Rosemberg, 1993; Kaizô e Teixeira, 2004). Marteleto e Miranda (2004), por exemplo, mostram que a escolaridade média das mulheres negras adultas ultrapassou a dos homens negros adultos antes mesmo que entre brancos. Com efeito, analisando os anos médios de escolaridade por raça e sexo em coortes de adultos ( 25 a 50 anos) de 1937 a 1969, os pesquisadores do CEDEPLAR (Centro de Desenvolvimento $e$ Planejamento Regional da Universidade Federal de Minas Gerais) mostram que a inflexão da curva das mulheres negras ocorre na coorte 1952 e a das mulheres brancas apenas na de 1958 (Marteleto e Miranda, 2004:11). Isto é, nessa faixa etária, as mulheres negras superaram a escolaridade dos homens negros antes de as mulheres brancas superarem a escolaridade dos homens brancos. Notam, ainda, que, no Brasil, os melhores indicadores educacionais das mulheres frente aos dos homens não é algo recente: para as coortes consideradas, isto se observa desde a década de 1950.

Os melhores indicadores educacionais das mulheres brancas, negras e indígenas são particularmente notáveis no ensino superior. Kaizô e Teixeira (2004), analisando o percentual da população de 10 anos e mais com nível superior por cor/raça e sexo na série histórica censitária 1960-2000 (Tabela 3), evidenciam: a) aumento na escolaridade superior para todos os segmentos de cor/raça; b) persistência de uma ordenação dos valores para os segmentos de cor/raça na seqüência amarelos e brancos com porcentagens acima da média nacional e pardos, pretos $e$ indígenas (estes últimos, exceto no Censo 2000) abaixo da média nacional; c) inflexão da curva de escolaridade superior das 
mulheres em 2000, quando, para o Brasil como um todo e para todos os segmentos de cor/raça (com exceção do amarelo), o percentual das mulheres com nível superior é superior ao dos homens. Porém, esta inflexão já se notava no Censo 1991 para os segmentos preto e pardo.

Tabela 3

Porcentagem da população de dez anos e mais com nível superior por sexo, cor/raça e ano censitário. Brasil.

\begin{tabular}{|l|c|c|c|c|c|c|c|c|}
\hline \multirow{2}{*}{$\begin{array}{l}\text { Cor/raça } \\
\text { letnia }\end{array}$} & \multicolumn{2}{|c|}{1960} & \multicolumn{2}{c|}{1980} & \multicolumn{2}{c|}{1991} & \multicolumn{2}{c|}{2000} \\
\cline { 2 - 9 } & $\mathrm{H}$ & $\mathrm{M}$ & $\mathrm{H}$ & $\mathrm{M}$ & $\mathrm{H}$ & $\mathrm{M}$ & $\mathrm{H}$ & $\mathrm{M}$ \\
\hline Branca & 1,38 & 0,22 & 3,84 & 2,52 & 6,03 & 5,25 & 6,57 & 6,60 \\
\hline Preta & 0,03 & 0,01 & 0,27 & 0,23 & 0,93 & 0,96 & 1,24 & 1,58 \\
\hline Amarela & 0,55 & 0,19 & 10,55 & 6,61 & 18,89 & 14,79 & 21,11 & 18,33 \\
\hline Parda & 0,11 & 0,02 & 0,54 & 0,43 & 1,15 & 1,16 & 1,29 & 1,55 \\
\hline Indígena & - & - & - & - & 0,78 & 0,73 & 1,37 & 1,40 \\
\hline Total & 0,87 & 0,14 & 2,41 & 1,64 & 3,72 & 3,42 & 4,19 & 4,46 \\
\hline
\end{tabular}

Fonte: Censos Demográficos apud Kaizô e Teixeira (2004: 18, tabelas 7 e 8).

Os dados de matrícula no ensino superior fornecidos pelo INEP sobre os anos 1996 e 2003 (Godinho et alii, 2006) - que focalizam população mais próxima em idade a dos/as candidatos/as ao Programa IFP - apresentam a mesma tendência: maior presença feminina que masculina nas matrículas do ensino superior em ambos os anos (1996 e 2003); tendência que se acentuou em 2003, observada em todas as regiões fisiográficas e, em 2003, mais acentuada nas regiões Norte, Nordeste e Centrooeste (Tabela 4). 
Ação afirmativa no ensino superior brasileiro

Tabela 4

Matrículas no ensino superior por sexo e região. Brasil, 1996 e 2003.

\begin{tabular}{|c|c|c|c|c|c|c|c|c|c|c|c|c|}
\hline \multirow[t]{2}{*}{ Região } & \multicolumn{5}{|c|}{1996} & \multicolumn{5}{|c|}{2003} & \multicolumn{2}{|c|}{$\begin{array}{c}\text { Razão de } \\
\text { sexo } \\
(\mathrm{H} / \mathrm{M}) \\
\end{array}$} \\
\hline & Mulheres & $\%$ & Homens & $\%$ & Total & Mulheres & $\%$ & Homens & $\%$ & Total & 1996 & 2003 \\
\hline Norte & 40.090 & 52,0 & 37.079 & 48,0 & 77.169 & 139.582 & 60,6 & 90.645 & 39,4 & 230.227 & 0,92 & 0,65 \\
\hline Nordeste & 155.468 & 55,6 & 123.960 & 44,4 & 279.428 & 354.930 & 56,8 & 269.762 & 43,2 & 624.692 & 0,80 & 0,76 \\
\hline Centro-oeste & 77.821 & 57,9 & 56.621 & 42,1 & 134.442 & 221.299 & 60,0 & 147.607 & 40,0 & 368.906 & 0,73 & 0,67 \\
\hline Sul & 190.897 & 54,7 & 158.296 & 45,3 & 349.193 & 412.574 & 55,4 & 332.590 & 44,6 & 745.164 & 0,83 & 0,81 \\
\hline Sudeste & 551.624 & 53,6 & 476.673 & 46,4 & 1.028 .297 & 1.064 .861 & 55,5 & 853.172 & 44,5 & 1.918 .033 & 0,86 & 0,80 \\
\hline Brasil & 1.015 .900 & 54,4 & 852.629 & 45,6 & 1.868 .529 & 2.193.246 & 56,4 & 1.693 .776 & 43,6 & 3.887 .022 & 0,84 & 0,77 \\
\hline
\end{tabular}

Fonte: INEP/MEC apud Godinho et al (2006:141). 
O diferencial em favor das mulheres assume contornos mais acentuados quando se analisam os dados sobre concluintes: em 2002 , enquanto $56,5 \%$ das matrículas no ensino superior eram de mulheres, o percentual de mulheres sobe para $62,9 \%$ entre os concluintes (INEP, 2002, apud Godinho et alii, 2006).

Em síntese, os dados apresentados até agora permitem apontar, no cenário brasileiro: superior;

- maior presença feminina que masculina no ensino

- melhor aproveitamento escolar das mulheres no ensino superior que o dos homens;

- tendência mais acentuada nas matrículas em estabelecimentos situados nas regiões Norte, Nordeste e Centrooeste;

- tendência mais acentuada, atualmente (2000), entre pretos, pardos e indígenas que entre brancos.

Essa análise permite sugerir que a composição sexual do conjunto de candidatos/as ao Programa IFP é compatível com as tendências nacionais e que parecem potencializadas pelos critérios de ação afirmativa que adotamos: cor/raça e região. Isto é, a sobre-representação de mulheres entre candidatas do Programa IFP parece decorrer do fato de que, no Brasil, mais mulheres que homens - especialmente entre negros/as e indígenas residentes nas regiões Norte, Nordeste e Centro-Oeste - freqüentam e terminam o ensino superior. Portanto, se a tendência nacional apontada permanecer nos próximos anos, temos forte probabilidade de assistir, no Programa IFP, a manutenção ou o aumento da participação de mulheres entre os/as candidatos/as, pois os critérios para ação afirmativa (região e cor/raça), adotados pelo Programa IFP no Brasil, correspondem aos segmentos sociais nos quais se observa maior e crescente percentual de mulheres no ensino superior.

Porém, queremos chamar a atenção para outro ponto: o da composição de cor/raça dos/as candidatos/as. Ao analisar a declaração de cor/raça dos/as candidatos/as nas diferentes 
Ação afirmativa no ensino superior brasileiro

seleções, nota-se uma contínua diminuição dos/as candidatos/as que se autodeclaram brancos/as e amarelos/as (não privilegiados pelo edital) e, obviamente, uma proporção sempre maior de candidatos/as que se autodeclaram negros/as (pretos/as ou pardos/as) e indígenas. Isto é, aparentemente, foi ocorrendo seja um aumento dos/as candidatos/as desses grupos de cor/raça, seja uma aprendizagem de como se apresentar a esse Programa de ação afirmativa que privilegia os "desiguais". A divulgação do perfil dos/as selecionados/as, bem como seu uso em material de divulgação (site, folder, cartaz) - judiciosamente notado por Sandra Azerêdo em seu artigo Mestiçagem, igualdade e afirmação da diferença $a^{5}$ - deve ter contribuído para tal aprendizagem (Tabela 5).

\section{Tabela 5}

Distribuição de freqüência (\%) de candidatos/as ao Programa IFP por cor/raça e ano da seleção. Brasil.

\begin{tabular}{|l|r|r|r|r|r|}
\hline \multirow{2}{*}{ Cor/raça } & \multicolumn{5}{|c|}{ Ano da seleção } \\
\cline { 2 - 6 } & 2002 & 2003 & 2004 & 2005 & 2006 \\
\hline Branca & 36.9 & 33.0 & 25.6 & 22.5 & 19.7 \\
\hline Amarela & 0.5 & 0.9 & 0.8 & 1.6 & 1.0 \\
\hline Preta & 30.6 & 31.2 & 35.5 & 35.5 & 39.4 \\
\hline Parda & 29.1 & 32.7 & 34.4 & 36.8 & 35.2 \\
\hline Indígena & 2.7 & 1.5 & 3.1 & 2.8 & 4.3 \\
\hline Não informada & 0.2 & 0.9 & 0.7 & 0.7 & 0.5 \\
\hline Total & 100.0 & 100.0 & 100.0 & 100.0 & 100.0 \\
\hline
\end{tabular}

Fonte: Base de dados do Programa Internacional de Bolsas de PósGraduação da Fundação Ford, Brasil (FCC, 2007).

5 "Olhando as fotos das/os bolsistas no cartaz do programa de ação afirmativa para a pós-graduação da Fundação Ford, na porta de meu gabinete, não vejo um Brasil dividido entre brancos e pretos. Essas fotos contrastam gritantemente com a foto higienizada da 'nova face da América' representada pela mulher na capa da revista Time. E penso no enfrentamento agonístico que é a condição da existência da democracia. Imagino os perigos e a bagunça que vamos ter que enfrentar nas universidades com a introdução da política de cotas, sentindo uma grande satisfação de finalmente estarmos 'aqui embaixo' começando a desmascarar o segredo da graça de dançar em um regime de indefinição, que tem machucado e destruído tanta gente no Brasil" (Azerêdo, 2005:325). 
Porém, quando comparamos as curvas de homens e de mulheres, verificamos que a presença de homens "estranhos ao ninho" - isto é, daqueles que se afastam do perfil de cor/raça privilegiado pelo edital - cai mais intensamente que a das mulheres. Ou seja, aparentemente, homens que não apresentam os atributos privilegiados pelo edital desistem mais (isto é, não concorrem) que as mulheres. Notamos, em números absolutos $e$ percentuais, que mais mulheres do que homens fora dos gruposalvo candidataram-se ao Programa IFP nas cinco primeiras seleções (Gráfico 1).

\section{Gráfico 1}

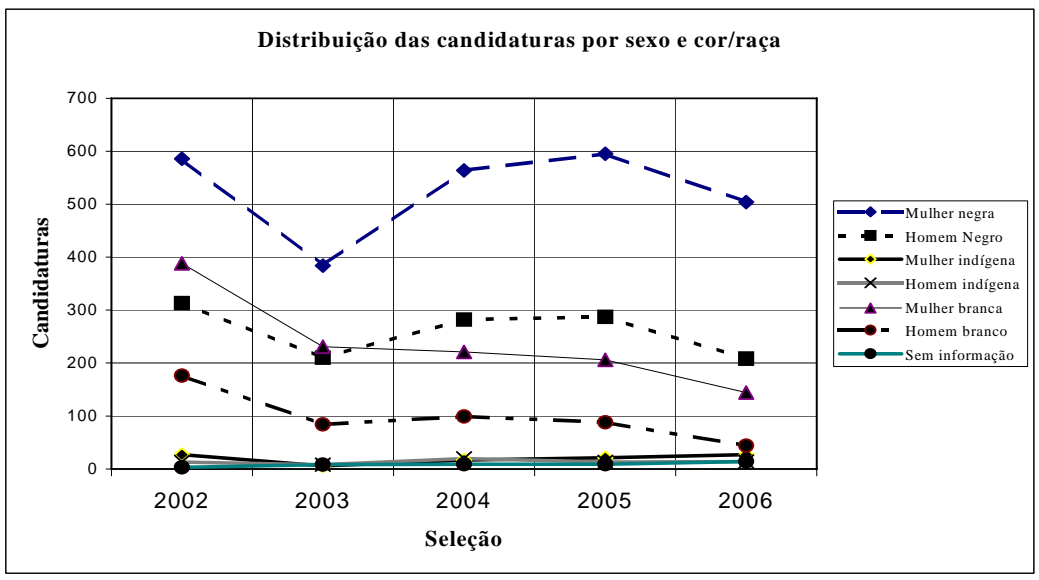

Fonte: Base de dados do Programa Internacional de Bolsas de OpósGraduação da Fundação Ford, Brasil (FCC, 2006). 
Ação afirmativa no ensino superior brasileiro

Isso se torna bem evidente quando calculamos a razão de sexo (número de homens/número de mulheres) para cada seleção (Gráfico 2).

\section{Gráfico 2}

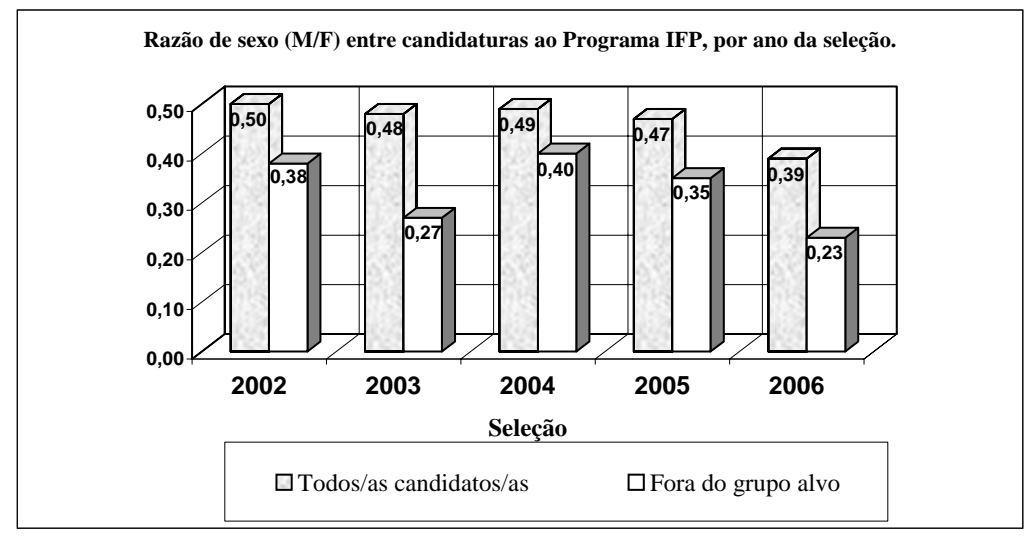

Fonte: Base de dados do Programa Internacional de Bolsas de PósGraduação da Fundação Ford, Brasil (FCC, 2006).

Uma forma de interpretar esta diferença é que mulheres, mais que homens, "tentaram a sorte", seriam mais pró-ativas ou evidenciaram uma "energia suplementar" no prosseguimento de sua escolaridade superior, qualificativo já utilizado por Baudelot $e$ Establet (1993) no livro Allez les Filles. Neste sentido, mais mulheres que homens teriam desafiado as regras do jogo do Programa IFP.

Este desafio, desenvolvemos a segunda linha de argumentos, poderia também ter sido encorajado pela frase que constava do edital até 2006: "no Brasil, o Programa além de estar atento à igualdade de gênero, destina-se, prioritariamente, a ...". É possível que, mesmo mulheres que não se enquadravam no perfil privilegiado pelo edital, sentiram-se mais autorizadas a se 
candidatarem a um programa de ação afirmativa porque, enquanto mulheres, se consideram "sempre discriminadas". Complementarmente, é possível que a frase "estar atento à igualdade de gênero" tenha inibido homens "estranhos ao ninho" a se candidatarem, pois não se perceberiam acolhidos por um programa "atento à igualdade de gênero". Além disso, paradoxalmente, homens, mais que mulheres, se adaptariam às regras do jogo do Programa IFP.

Nesse sentido, "estar atento à igualdade de gênero", como algo que privilegiaria ou atentaria para as mulheres, tem sido a interpretação privilegiada em diversas instituições sociais academia, mídia, governo e militância - que, muitas vezes, igualam gênero a mulher $e$ adotam um modelo linear de compreensão das desigualdades de gênero. Isto porque, no Brasil, a busca de compreensão simultânea das hierarquias de gênero, raça e classe tem se baseado, muitas vezes, em modelo paritário $e$ cumulativo, esperando-se uma associação linear entre os eixos de desigualdade, como venho sugerindo nos últimos anos (Rosemberg, 2001). Tal modelo associativo e paritário não dá conta, porém, da complexidade e das contradições observadas nas instituições educacionais onde as dinâmicas de gênero, raça, classe e idade não são redutíveis umas às outras, evidenciando, muitas vezes, um movimento não sincrônico, não cumulativo de desigualdades e resistência a elas.

Scott já havia apontado equívocos na suposição de "paridade" entre os três termos (classe, raça e gênero) em teorias feministas, quando

na verdade, eles não têm um estatuto equivalente. Enquanto a categoria "classe" tem seu fundamento na elaborada teoria de Marx (e seus desenvolvimentos ulteriores) sobre a determinação econômica $e$ a mudança "histórica", "raça" e "gênero" não carregam associações semelhantes (Scott, 1995:73). 
Ação afirmativa no ensino superior brasileiro

Considero que o conceito de não-sincronia proposto por Hicks (1981) possibilita apreender melhor o jogo de conflitos, tensões e contradições inter e intra-institucionais: "indivíduos (ou grupos) em suas relações com os sistemas político e econômico não compartilham da mesma consciência ou das mesmas necessidades no mesmo momento" (Hicks, 1981:221). Isso significa que a interseção dessas relações pode levar a interrupções, descontinuidades, alterações ou incremento do impacto original das dinâmicas de raça, classe, gênero ou idade em dado contexto social ou institucional. Nem as pessoas individualmente, nem os movimentos sociais desenvolvem em perfeita sincronia consciência de classe, gênero, raça e idade. Por exemplo, a busca de superação de desigualdades de gênero pode ignorar, ou mesmo apoiar-se, em desigualdades de raça. Além disso, é possível supor que as desigualdades não são sincrônicas nos diversos campos sociais e nos diversos momentos da trajetória de vida de uma pessoa.

O conceito de não-sincronia (ou de heterocronia) nas dimensões de gênero e raça deve ser judiciosamente considerado quando se analisam as oportunidades no sistema educacional brasileiro, pois o modelo "associativista" (gênero e raça teriam um impacto cumulativo em todas as instituições ou esferas sociais) sobre desigualdades educacionais brasileiras não se sustenta em base empírica, como um de nós vem mostrando (Rosemberg, 2001) $e$ apontaremos aqui.

Encaminhamos nossas reflexões para seu término: como enfrentar a tensão? Como traduzir, na prática social, a sugestão de Scott,

Faz mais sentido perguntar como os processos de diferenciação social operam e desenvolver análises de igualdade e discriminação que tratem as identidades não como entidades eternas, mas como efeitos de processos políticos e sociais? (Scott, 2005:13). 
Isto é, quando adotamos a perspectiva da "transversalidade do gênero" em políticas e projetos sociais, estamos nos referindo a homens $e$ a mulheres ou apenas a mulheres? Estamos nos referindo a processos que ocorrem em qual contexto político $e$ social? Estaríamos atentos/as ao atual contexto brasileiro de expansão do ensino superior, com suas particularidades e que debate e implanta programas de ação afirmativa? Como proceder em programas de ação afirmativa, quando os indicadores sociais, como os da educação, são favoráveis às mulheres? Estaria a sociedade brasileira, neste momento de debate sobre ação afirmativa no ensino superior, apta a estabelecer sub-cotas para homens e para mulheres no acesso à universidade? E cotas para homens na educação seriam justas, politicamente adequadas quando o sistema educacional privilegia as mulheres, mas o mercado de trabalho penaliza o salário de mulheres educadas?

Como estamos iniciando uma nova experiência de política educacional com a introdução de estratégias de ação afirmativa, consideramos oportuno trazer a perspectiva de gênero em sua complexidade para este novo debate no ensino superior brasileiro, mesmo que não se trate de "problema fácil de ser resolvido". Mesmo que se receba a "condenação penosa" de "mulher que somente tem paradoxos" a oferecer (Gouges, 1791, apud Scott, 2005:2).

\section{Referências bibliográficas}

AzERÊDO, Sandra. Mestiçagem, igualdade e afirmação da diferença pensando a política de cotas na universidade. Revista Estudos Feministas, vol. 13, n 3, set.-dez. 2005, pp.320-325.

BARCELOS, Luiz. C. Educação e desigualdades raciais no Brasil. Cadernos de Pesquisa, vol. 18, no 37, ago. 1993, pp.15-24.

Baudelot, Christian e Establet, Roger. Allez les filles. Paris, Seuil, 1992. 
Ação afirmativa no ensino superior brasileiro

FERES JÚNIOR, João e ZONINSEIN, Jonas. (orgs.) Ação afirmativa $e$ universidade: experiências nacionais comparadas. Brasília, Universidade de Brasilia, 2006.

Fundação CARlos Chagas (FCC). Base de dados do Programa Internacional de Bolsas de Pós-Graduação da Fundação Ford. São Paulo, FCC, 2006 e 2007.

GodinHO, Tatau et al (org.) Trajetória da mulher na educação brasileira: 1996-2003. Brasília, INEP, 2006.

IFP - PROgRama Internacional de Bolsas de Pós-graduaÇão DA FunDAÇÃo FORD. Edital. São Paulo, FCC, 2006.

KAIZÔ, Iwakami B. e TEIXEIRA, Moema de Poli. O vermelho e o negro: raça e gênero na universidade brasileira - uma análise da seletividade das carreiras a partir dos censos demográficos de 1960 a 2000. Rio de Janeiro, IPEA, 2004.

HICKS, Emily. Cultural Marxism: nonsynchrony and Feminist Practice. In: SARGENT, L. (org.) Women and revolution. Boston, Southend Press, 1981, pp.219-237.

LIGoCKI, Malô S. L. e LiBARDONI, Marlene. (ed.) Discriminação positivaações afirmativas: em busca da igualdade. Brasília, CFEMEA, 1995.

MARTELETO, Letícia J. e MIRANDA, Vitor F.O. de. Diferenças educacionais entre coortes de adultos no século $\mathrm{XX}$ : o papel do sexo e da raça. Trabalho apresentado no XIV Encontro Nacional de Estudos Populacionais, ABEP, em Caxambu, MG, de 20-24 de setembro de 2004.

Revista Estudos Feministas. Dossiê Ações Afirmativas, vol. 4, $\mathrm{n}^{\circ} 1$, 1996, pp.124-221.

RochA, Edmar \& ROSEMBERG, Fúlvia. Auto-declaração de cor/raça entre escolares paulistanos(as). Cadernos de Pesquisa, vol. 37, no 132, set./dez. 2007, pp.759-800.

ROSEMBERG, Fúlvia. Subordinação de gênero e alfabetização no Brasil. Idéias (19) - Alfabetização: passado, presente e futuro, São Paulo, FDE, 1993.

Políticas educacionais e gênero: um balanço dos anos 1990. Cadernos Pagu (16), Campinas-SP, Núcleo de Estudos de Gênero, 2001, pp.151-198. 
Fúlvia Rosemberg e Leandro Feitosa Andrade

ScotT, Joan W. O enigma da igualdade. Revista Estudos Feministas, vol. 13, no 3, set.-dez. 2005, pp.11-30.

. Gênero: uma categoria útil de análise histórica. Educação e Realidade, vol. 20, nº 2, Porto Alegre, jul./dez. 1995, pp.71-99. 